\title{
A Dietary Supplement Containing Standardized Phaseolus vulgaris Extract Influences Body Composition of Overweight Men and Women
}

\author{
Leonardo Celleno ${ }^{1}$, Maria Vittoria Tolaini ${ }^{1}$, Alessandra D'Amore ${ }^{1}$, Nicholas V. Perricone 2 , Harry G. \\ Preuss $^{3}$
}

1. Cosmetic Research Center, dell'Università Cattolica di Roma, Rome, Italy

2. NV Perricone, MD, Ltd, Meriden, CT 06450, USA

3. Georgetown University Medical Center, Department of Physiology, Washington, DC 20057, USA

Correspondence to: Harry G. Preuss MD, Professor of Physiology, Medicine, \& Pathology, Basic Science Building, Room 231B, Georgetown University Medical Center, Washington, DC 20057.preusshg@georgetown.edu

Received: 2006.12.13; Accepted: 2007.01.23; Published: 2007.01.24

Background: More than one billion human adults worldwide are overweight and, therefore, are at higher risk of developing cardiovascular diseases, diabetes, and a variety of other chronic perturbations. Many believe that use of natural dietary supplements could aid in the struggle against obesity. So-called "starch blockers" are listed among natural weight loss supplements. Theoretically, they may promote weight loss by interfering with the breakdown of complex carbohydrates thereby reducing, or at least slowing, the digestive availability of carbohydrate-derived calories and/or by providing resistant starches to the lower gastrointestinal tract.

Aims: The present research study examines a dietary supplement containing $445 \mathrm{mg}$ of Phaseolus vulgaris extract derived from the white kidney bean, previously shown to inhibit the activity of the digestive enzyme alpha amylase, on body composition of overweight human subjects.

Methods: A randomized, double-blinded, placebo-controlled study was conducted on 60 pre-selected, slightly overweight volunteers, whose weight had been essentially stable for at least six months. The volunteers were divided into two groups, homogeneous for age, gender, and body weight. The test product containing Phaseolus vulgaris extract and the placebo were taken one tablet per day for 30 consecutive days before a main meal rich in carbohydrates. Each subject's body weight, fat and non-fat mass, skin fold thickness, and waist/hip/thigh circumferences were measured.

Results: After 30 days, subjects receiving Phaseolus vulgaris extract with a carbohydrate-rich, 2000- to 2200-calorie diet had significantly $(\mathrm{p}<0.001)$ greater reduction of body weight, BMI, fat mass, adipose tissue thickness, and waist,/hip/ thigh circumferences while maintaining lean body mass compared to subjects receiving placebo.

Conclusion: The results indicate that Phaseolus vulgaris extract produces significant decrements in body weight and suggest decrements in fat mass in the face of maintained lean body mass.

Key words: starch blockers, weight loss, obesity, amylase inhibitors, bean extract

\section{Introduction}

Excess accumulation of body fat (overweight/obesity), a chronic disequilibrium between food consumption and energy expenditure, is becoming noticeably more prevalent [1-4]. This is unfortunate for more reasons than just poor physical appearance, because the overweight/obesity states increase the risk of hypertension, type II diabetes, arthritis, elevated circulating cholesterol, cancer, serious hormonal imbalances in women that can lead to sterility, chronic renal disease, and even dementia and Alzheimer's disease $[1,5-10]$. Although it took an inordinate length of time for widespread realization, it is now generally recognized that overweight/obesity have reached epidemic proportions in the United States [11]. Further, this health problem is not limited to America, because globally there are over one billion overweight adults according to many including the
World Health Organization (WHO) [12,13].

Strategies to lose body fat typically involve a combination of dietary changes limiting caloric intake, increased physical activity, behavioral therapy, pharmacotherapy, and, in extreme cases, surgery [1]. Although the availability and popularity of natural dietary supplements intended to help with weight loss has risen dramatically in recent years, their therapeutic effectiveness remains uncertain in many cases. Some providers of weight loss products tend to over-hype the utility of dietary supplements without sufficient evidence, while many academic individuals refuse to believe that natural weight-loss products have any therapeutic usefulness. Among potentially useful supplements to obtain healthy body proportions are those containing "starch blockers," because over-consumption of rapidly-absorbed carbohydrates is frequently associated with obesity [14]. Theoretically, starch blockers could promote weight loss by 
interfering with and/or slowing the breakdown of complex carbohydrates, thereby reducing the digestive availability of carbohydrate-derived calories, at least early on, and/or favorably influencing the glucose-insulin system [15-20]. Also recent reports suggest the possibility that "resistant starches' may play an important role in body weight loss [21].

The present paper reports findings from a randomized, double-blinded, placebo-controlled investigation in which body weight and body fat composition of generally healthy, overweight human volunteers were examined before and after a 30-day oral treatment with placebo or a test formula containing a starch blocker as the principal active ingredient. [Phase 2 Starch Neutralizer ${ }^{\mathrm{TM}}$, also known as Phaseolamin $2250^{\mathrm{TM}}$ and Phase $2^{\mathrm{TM}}$ (Pharmachem Laboratories, Inc., NJ)].

Table 1. Exclusion and Inclusion Criteria

\section{Methods}

\section{Study Design}

EVIC ITALIA in Rome, Italy performed this randomized, double-blinded, placebo-controlled study in accordance with the Helsinki Declaration and other applicable laws related to the protection of study subjects. Volunteers were recruited through a market research company in Rome, Italy from a group of individuals who expressed a willingness to participate in such evaluations. Eighty-two subjects, aged from 20-45, found to be slightly overweight were selected initially. Overweight was calculated using the following formula: ideal weight $(\mathrm{kg})=100 /(100-\%$ normal body fat) $x$ lean mass. After calculating ideal weight, the overweight mass was estimated by measured body weight - ideal weight. The selection criteria listed in Table 1 were used to exclude or include study candidates.

\section{Exclusion criteria}

- Pregnant or breastfeeding females

- Weight-reduction treatments during the 6 months prior to the study

- Any condition contrary to those indicated in the enrolment criteria

Inclusion criteria

- 5 to $15 \mathrm{~kg}$ overweight

- Consistently stable body weight for at least 6 months

- Weight stability throughout a 30-day pre-treatment period

- Good general health

- No ongoing drug treatments

- Commitment to eating as prescribed by the nutritionist

- Commitment to avoiding the use of other weight loss products during study

- Commitment to avoid any changes in lifestyle throughout the test period

(including sports and any activity that might affect test results)

- Non-participation in other similar tests during the 6 months prior to the study

Prior to the initiation of study, each subject was questioned concerning the above exclusion and inclusion criteria.

In order to obtain optimal compliance among subjects, it was deemed helpful to pre test participants, i.e., would a given individual comply by maintaining the overall diet and taking one tablet before a meal rich in carbohydrates? After providing written informed consent, each volunteer was examined by a physician with expertise in nutrition, and given a sheet with nutritional recommendations to be followed, including a daily intake of complex carbohydrates concentrated in one of two main meals (Table 2).
The study diet provided approximately 2000 to 2200 calories per day. All volunteers agreed to follow the nutritionist's recommendations. The candidates were entered into a 2-week single-blinded, run-in to enrollment and randomization. Subjects in this run-in period unknowingly received just placebo: the investigators were aware that participants received inactive ingredients.

Sixty subjects from the original 82 with proven body weight stability and deemed to be most compliant with the expected criteria were subsequently selected for the study itself. The chosen participants reported to the Center after 10, 20, and 30 days to have 
their body weight checked and recorded. The two groups took the assigned tablets, one tablet per day before the main meal rich in complex carbohydrates for 30 consecutive days (Table 2).

The two provided tablet formulas were identified by the sponsor as Blokcal batch D106B (Test) and Blokcal batch 1600301 (Placebo). Tablets were identical in appearance so that the test and placebo tablets were indistinguishable. An envelope containing the sam- ple's qualitative-quantitative formulas and the product identification key was delivered to the principal investigator and kept at the disposal of the researchers during the test period for any unexpected circumstances. Upon completion of the study, the envelope was opened in the presence of a representative of the sponsor and of the Principal Investigator, and the representative formulas of the samples were identified.

Table 2 A general summary of the meal plan used in the current study.

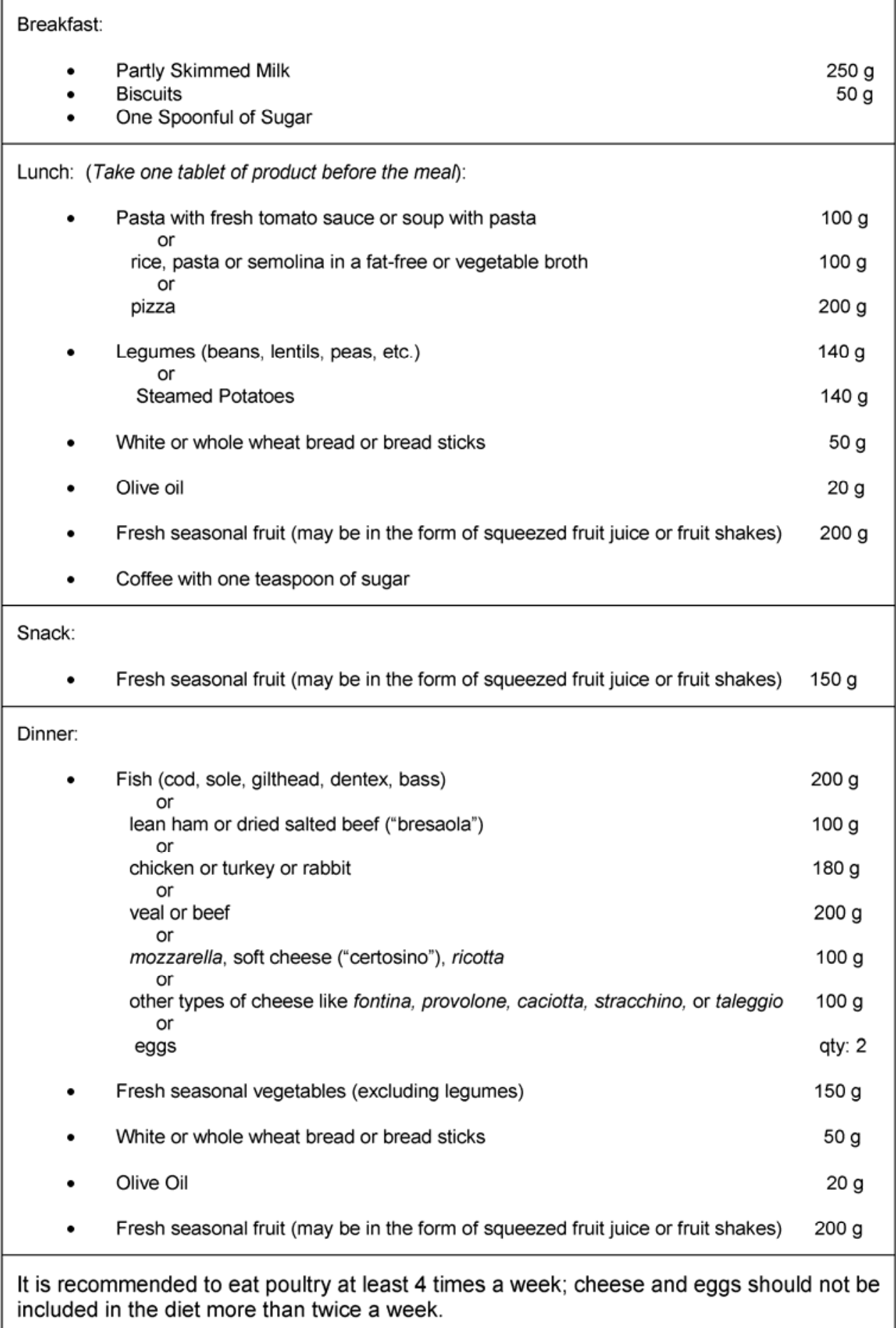




\section{Test Products}

The active substance to be tested was an $800-\mathrm{mg}$ tablet (Blokcal D106B) containing approximately $445 \mathrm{mg}(56 \% w / w)$ of Phase 2 Starch Neutralizer IV, a dried aqueous extract of the common bean (Phaseolus vulgaris). Phase 2 had been standardized to a minimum of 3000 AAlU (alpha-amylase inhibiting units), validated by a modified USP method (SOP 110, Rev. 5). Other ingredients present in this preparation were calcium phosphate $(20 \%)$, microcrystalline cellulose $(10 \%)$, vitamin B3 $(7 \%)$, as well as small amounts $(3 \%)$ of various other ingredients, including chromium picolinate $(0.5 \mathrm{mg} /$ tablet $)$. Accordingly, each tablet contained roughly $50-60 \mathrm{mcg}$ of elemental chromium per serving.

The control substance was an $800-\mathrm{mg}$ tablet (Blokcal 1600301) containing primarily microcrystalline cellulose and maltodextrin (45\% w/w each). Other ingredients included relatively small amounts $(\sim 3 \%)$ of Si/ybum marianum (milk thistle), cacao, silicon dioxide, magnesium stearate, and Curcuma longa (turmeric) as a coloring agent.

\section{Measurements}

Body weight and impedance measurements, skin echogram, and waist, hip, and thigh circumferences were measured at the beginning and end of the 30-day treatment phase. BMI was calculated as the body weight in kilograms divided by the square of the height in meters.

\section{Bodv Weight and Composition}

Body weights, performed on undressed individuals, were measured using a calibrated Bodymaster Scale (Rowenta) that also enabled calculation of the body composition (fat mass, lean body mass) through bioelectric leg-to-leg impedance measurements. The patented "foot pad" design sends a low, safe electrical current through the body to measure its composition. The electrical current passes more easily through lean muscle than fat. Body composition is calculated mathematically, based upon the speed at which the signal passes through the body [22-25].

\section{Skin Echogram}

A 7 Mhz linear probe and a 100 MP Logic Echograph (GE Medical Systems) was used to examine the morphology and thickness (in $\mathrm{mm}$ ) of subcutaneous tissue in areas where adipose tissue tends to accumulate, i.e., the abdominal region for men and the right trochanter region for women. The accuracy of the Skin Echography is reported by the manufacturer to be \pm one $\mathrm{mm}$.

\section{Waist. Hip. and Thigh Circumferences}

The respective circumference of the waist, hips, and right thigh was measured using a standard non-stretchable flexible measuring tape. Temporary tattoos were used to identify the area of reference from one reading to the next.

\section{Adverse/Side Effects}

The study staff monitored subjects throughout the investigation for the occurrence of any adverse or side effects.

\section{Statistical Analysis}

To minimize differences in beginning values between subjects, they were stratified into two groups very similar in size, age, gender, and body weight distribution. At completion, data from 30 subjects receiving the Test supplement and 29 subjects receiving the Placebo supplement were available for statistical analysis. For each subject, the differences between pre-treatment (baseline) and post-treatment (30-day) values for each parameter (body weight, lean body mass, etc.) were calculated. The differences were always obtained by subtracting the 30-day values from the baseline values. A negative difference indicates a reduction in the parameter after 30 days. Conversely, a positive difference indicates an increase in that parameter. This approach allowed test variability to remain low and the statistical analysis to be more powerful. The differences between pretreatment and 30 -day values in each of the two groups were analyzed using the paired Student's t-test (intragroup analysis). The differences in the deltas between the test and placebo group were analyzed by the unpaired t-test (intergroup analysis).

\section{Results}

The Test and Placebo groups were essentially comparable in starting age, gender, BMI, weight, fat mass, non-fat mass and various body circumferences (Table 3). There was a trend for a lesser skin echogram in the placebo group. One subject in the Placebo group withdrew from the study for unexplained reasons. No significant adverse events were reported.

Table 3. Baseline Measures of the Test and Control Groups

\begin{tabular}{|c|c|c|c|}
\hline Outcome & $\begin{array}{c}\text { Test } \\
(\mathrm{N}=30)\end{array}$ & $\begin{array}{c}\text { Placebo } \\
(\mathrm{N}=29)\end{array}$ & P Value \\
\hline Age (years) & $33.7 \pm 1.6$ & $34.2 \pm 1.6$ & 0.84 \\
\hline Gender & $22 \mathrm{~F} / 8 \mathrm{M}$ & $20 \mathrm{~F} / 9 \mathrm{M}$ & \\
\hline BMI $\left(\mathrm{kg} / \mathrm{m}^{2}\right)$ & $25.9 \pm 2.0$ & $26.0 \pm 2.3$ & 0.42 \\
\hline Weight $(\mathrm{kg})$ & $74.1 \pm 2.1$ & $73.4 \pm 2.4$ & 0.82 \\
\hline Fat Mass $(\mathrm{kg})$ & $23.0 \pm 0.8$ & $22.0 \pm 0.8$ & 0.39 \\
\hline Non Fat Mass $(\mathrm{kg})$ & $51.2 \pm 2.0$ & $51.5 \pm 2.0$ & 0.99 \\
\hline Skin Echogram $(\mathrm{mm})$ & $33.1 \pm 1.8$ & $28.6 \pm 1.7$ & 0.08 \\
\hline Waist Circumference $(\mathrm{cm})$ & $85.3 \pm 1.8$ & $87.4 \pm 3.1$ & 0.55 \\
\hline Hip Circumference $(\mathrm{cm})$ & $106.4 \pm 1.4$ & $106.5 \pm 1.5$ & 0.93 \\
\hline Right Thigh Circumference $(\mathrm{cm})$ & $65.8 \pm 1.5$ & $65.9 \pm 1.7$ & 0.97 \\
\hline
\end{tabular}

Ave \pm SEM is shown with the exception of gender where the ratio is given. Values for the listed outcomes are in parentheses. Only in the skin echogram was there a trend toward a statistically significant difference.

The results were examined within each group. While all subjects receiving the active supplement (Test) experienced some weight loss and reduction in fat mass (estimated via bioelectric impedance), adipose tissue thickness (via skin echogram), and waist, hip, and thigh circumferences, some participants in the placebo group actually showed increases in these parameters. Examining intragroup analysis of the changes in the Test group by the paired $t$ test, the following averages \pm SEM were found at the beginning 
and end of the study respectively: in kilograms --body weight $74.1 \pm 2.1$ vs. $71.2 \pm 2.0 \quad(\mathrm{p}<0.001)$; fat mass $23.0 \pm 0.8$ vs. $20.6 \pm 0.7 \quad(\mathrm{p}<0.001)$ and non-fat mass $51.2 \pm 2.0$ vs. $50.6 \pm 2.0(\mathrm{p}<0.001)$; in millimeters -- skin echogram $33.1 \pm 1.8$ vs. $29.3 \pm 1.7(p<0.001)$; in centimeters - waist circumference $85.3 \pm 1.8$ vs. $82.5 \pm 1.7$ $(\mathrm{p}<0.001)$, hip circumference $106.4 \pm 1.4$ vs. $104.9 \pm 1.4$ $(p<0.001)$, and right thigh circumference $65.4 \pm 1.5$ vs. $64.9 \pm 1.5(\mathrm{p}<0.001)$.

Examining intragroup analysis of the Control group by the paired $t$ test, the following averages \pm SEM were found at the beginning and end of the study respectively: in kilograms --body weight $73.4 \pm 2.4$ vs. $73.2 \pm 2.4(p<0.005)$; fat mass $22.0 \pm 0.8$ vs. $21.8 \pm 0.8(\mathrm{p}>0.05)$ and non fat mass $51.5 \pm 2.0$ vs. $51.3 \pm 2.0(p<0.02)$; in millimeters -- skin echogram $28.6 \pm 1.7$ vs. $28.0 \pm 1.7(p<0.04)$; in centimeters - waist circumference $87.4 \pm 3.1$ vs. $87.0 \pm 3.1(\mathrm{p}<0.004)$, hip circumference $106.5 \pm 1.5$ vs. $106.4 \pm 1.4(\mathrm{p}>0.05)$, and right thigh circumference $65.9 \pm 1.7$ vs. $65.7 \pm 1.7(p<0.008)$.

As Table 4 illustrates, there was a highly significant $(p<0.001)$ difference between the Test and Control groups after 30 days in all the changes of components measured, i.e., the group receiving the Test supplement containing Phaseolus vulgaris extract had much greater loss of body weight, fat mass, adipose tissue thickness, and waist, hip, and thigh circumference. The difference in mean lean body mass loss just proved significant $(\mathrm{p}<0.05)$.

Table 4. Effect of Phaseolus vulgaris-containing extract vs. control dietary supplement on the body composition of overweight subjects

\begin{tabular}{|c|c|c|c|}
\hline Measured Parameter & Test $(n=30)$ & $\begin{array}{l}\text { Control } \\
(n=29)\end{array}$ & p-value \\
\hline Body weight (kg) & $\begin{array}{c}-2.93 \pm \\
1.16\end{array}$ & $-0.35 \pm 0.38$ & $<0.001$ \\
\hline Fat mass $(\mathrm{kg})$ & $-2.4 \pm 0.67$ & $-0.16 \pm 0.33$ & $<0.001$ \\
\hline Lean body mass $(\mathrm{kg})$ & $-0.53 \pm 0.45$ & $-0.19 \pm 0.17$ & $<0.05$ \\
\hline $\begin{array}{l}\text { Waist circumference } \\
(\mathrm{cm})\end{array}$ & $-2.93 \pm 2.13$ & $-0.47 \pm 0.39$ & $<0.001$ \\
\hline Hip circumference $(\mathrm{cm})$ & $-1.48 \pm 0.66$ & $-0.10 \pm 0.47$ & $<0.001$ \\
\hline $\begin{array}{l}\text { Thigh (right) } \\
\text { circumference }(\mathrm{cm})\end{array}$ & $-0.95 \pm 0.80$ & $-0.26 \pm 0.46$ & $<0.001$ \\
\hline $\begin{array}{c}\text { Adipose tissue thick- } \\
\text { ness } \\
\text { (via skin echogram) } \\
(\mathrm{mm})\end{array}$ & $-4.2 \pm 6.51$ & $-0.66 \pm 2.81$ & $<0.001$ \\
\hline
\end{tabular}

Ave \pm SEM is shown. Among various parameters, a comparison of the individual changes within groups ( 30 day values - baseline) was made between the test and control groups. The negative values indicate a loss from baseline within the group. The significance of the 30-day changes between the test and control groups were compared via the unpaired Student's $t$ test and listed in the last column.

\section{Discussion}

Our results indicate that a test dietary formula containing $445 \mathrm{mg}$ Phase 2 Phaseolus vulgaris extract taken daily by overweight human subjects concurrently with a carbohydrate-rich portion of a 2000- to 2200 -calorie diet is more effective at reducing body weight and body fat mass than placebo. Importantly, the major weight changes are brought about more by fat loss rather than diminution in non-fat body mass as indicated by different means: impedance measurements, waist, hip and thigh measurements, and subcutaneous fat measurements. Earlier, Udani et al. [20] reported reduced body weights and serum triglycerides in 14 obese adults receiving $1500 \mathrm{mg}$ of Phaseolus vulgaris extract (Phase $2^{\mathrm{TM}}$ ) twice daily with meals for eight weeks. However, values did not reach statistical significance. The clearer statistical differences found in the present study compared to Udani's earlier report where larger doses of extract were used [20] may be due, at least in part, to the care taken to enroll subjects who would comply with a strict protocol.

The purpose of the run-in period was to exclude non-adherent subjects. Obviously, the power to detect a meaningful difference between the active intervention and control groups would be enhanced by removing non-adherent participants. We accept that the ultimately randomized participants will be less representative of the general population of patients. Because the purpose of this trial was to measure efficacy of the agent under study, we chose to measure our parameters under optimal circumstances. Future studies could examine effects under more regular conditions to test the overall effectiveness of the product [26]. Evidence suggesting strong adherence to the present protocol can be gathered from the statistically significant mass losses noted even in the Placebo group relegated to the same caloric-restricted diet as the Test group.

Many published studies concerning methods to combat obesity provide only scale weight loss as the principal end point. The assumption that scale weight loss is synonymous with fat loss, however, is not always true $[26,27]$. Scale weight decreases may reflect non fat mass loss as much as fat loss. In the present study, indications by many different measurements are that the weight loss is principally due to loss of fat mass. Leg to leg impedance measurements suggest this is true. Although not the "gold standard" like DEXA [26], perusal of the literature suggests this methodology gives a good first approximation [22-25]. In addition, the use of echograms to estimate subcutaneous adipose tissue and the changes in body circumference in various locations corroborate the conclusions derived from the impedance data.

Further evidence of significant fat loss can be seen in the changes of the calculated body mass index (BMI). BMI is a generally accepted marker of obesity health risk [28]. The lowest health-risk category is among individuals whose BMI's range from 20-25, and the highest risk category is found in individuals whose BMI's exceed 40. A BMI greater than 40, termed as "morbid obesity" or clinically severe obesity, affects more than 15 million Americans. In the test group, BMI was lowered from an initial 25.9 \pm 2.0 (SEM) to $24.9 \pm 1.9(\mathrm{SEM})(\mathrm{p}<0.001)$. The placebo group showed no statistical difference from the initial 26.0 2.3 (SEM) to $25.9 \pm 2.3$ (SEM) $(\mathrm{p}=0.79)$. Important to our argument, $\mathrm{BMI}$ is known to significantly relate to fat mass - more so than scale weight alone [29]. The marked loss of fat 
provided in the face of a much lesser changes in non-fat mass caused by the Test formula is exactly what most nutritionists desire.

How do the amylase inhibitors work? Before crossing the intestinal wall, all complex carbohydrates (i.e., starches) must be hydrolyzed to their monosaccharide units, in most cases glucose [14]. There are several enzymes involved in this process: a-amylase present in saliva and pancreatic juice, which converts complex carbohydrates into oligosaccharides, and various other enzymes (maltase, lactase, etc.) present in the brush border of the small intestine that convert these oligosaccharides to monosaccharides that can then be absorbed. Glucose and other monosaccharides generated through this process are transported via the hepatic portal vein to the liver. Monosaccharides that are not immediately utilized for energy are stored for future energy needs as glycogen in the liver or as fat (triglycerides) in adipose tissue, liver, and plasma [14].

We believe the mechanism behind the weight loss relies on the reported a-amylase-inhibiting activity of the Phaseolus vulgaris extract [15-19]. Phaseolus vulgaris extract has been shown in vitro to inhibit the activity of a-amylase and may help promote weight loss by interfering with the digestion of complex carbohydrates to simple, absorbable sugars, potentially reducing carbohydrate-derived calories [30,31]. Also, slowing of the rapid absorption of carbohydrates would favorably influence the insulin system that could, in turn, lead to lesser fat accumulation [27]. We have previously shown in a rat model the ability of so-called "carbohydrate blockers" to prevent early absorption of rice starch and sucrose and prevent insulin resistance [32].

There is yet another mechanism that could contribute to the weight loss. Some dietary carbohydrates have a physical form that makes them inaccessible to a-amylase and, therefore, resistant to digestion in the human gastrointestinal tract. These resistant starches enter the colon largely undigested, where they are fermented by colonic bacteria to produce short-chain fatty acids, carbon dioxide, and methane. Resistant starches yield approximately 50 to $80 \%$ of the energy obtained from glucose, the principal product of non-resistant starch digestion [14]. It has been reported that resistant starch consumption promotes lipid oxidation [21]. Suffice it to say, starch blockers send starch to distal digestive sites where they may have effects similar to the resistant starches [21].

Although the active formula used in the present investigation consisted of many ingredients, we believe virtually all of the effect on body fat loss derived from the bean extract in the preparation. If one peruses the list of other ingredients, it is apparent that only the chromium picolinate could be involved in any significant fat loss [33]. Nevertheless, the amount of chromium picolinate $(0.5 \mathrm{mg} /$ tablet $)$ present in the bean extract-containing formula should have had little influence on body composition due to the small dosing. The amount of elemental chromium in $0.5 \mathrm{mg}$ of chromium picolinate would amount to roughly 50-60 mcg supplementation per day. Changes in body composition measures following chromium picolinate use have been seen sporadically in some studies, but generally only at dose levels of $200 \mathrm{mcg} \mathrm{Cr}$ or greater [33-37]. Based on a review of several published human studies, Vincent [38] concluded that chromium picolinate supplementation has relatively little effect on body composition even if an exercise program is involved when given at larger daily doses than in the present study.

Raw Phaseolus vulgaris beans contain a variety of potentially toxic substances. In animals, reduced food intake, impaired weight gain, and even deaths have been noted. [39,40]. In humans, consumption of raw or undercooked kidney beans has been associated with transient, often severe gastrointestinal disturbances [41,42]. These effects have been largely attributed to phytohemagglutinens (PHA) present at high levels in raw beans. However, two facts are important here. PHA levels can be reduced considerably by cooking, and small white navy beans are reported to have negligible levels compared to colored beans, which possess high levels of PHA's. Suffice it to say, the extract used in our study (Phase $2^{\mathrm{TM}}$ ) is a standardized white kidney bean extract prepared using heated processing conditions to substantially inactivate hemagglutinating activity (HA) and trypsin inhibiting activity (TIA) while preserving alpha-amylase inhibiting ability. The established product is standardized to contain less than 3,400 HA units per gram and less than 40 TIA units per mg dry weight.

\section{Conclusion}

The results of this investigation show that, when taken daily by overweight human subjects with the carbohydrate-rich portion of a 2000- to 2200-calorie diet, a dietary formula containing Phaseolus vulgaris extract as the major ingredient produced significant decreases in body fat while essentially maintaining lean body mass. Phaseolus vulgaris extract appears to be a safe and effective aid to consider in weight loss/maintenance programs.

\section{Acknowledgments}

Dr. Celleno, Ms Tolaini and Dr. D'Amore carried out the research at the Cosmetic Research Center, dell'Università Cattolica di Roma in Italy. Pharmachem Laboratories, Inc of Philadelphia, PA supported these studies and received permission to publish the findings. With a few exceptions, the present paper follows the original study report, including the statistical analysis. Dr. Preuss and Dr. Perricone analyzed the data and played a significant role in the writing of the manuscript. Some sections have been modified and/or expanded for clarification.

\section{Conflict of Interests}

The authors declare no conflict of interests.

\section{References}

1. Bray GA. Obesity. In: Ziegler EE, Filer LJ Jr, eds. Present Knowledge in Nutrition. Washington, DC: ILSI Press. 
1996:19-32.

2. Vastag B. Obesity is now on everyone's plate. JAMA 2004; 291:1186-1188.

3. Public Health Service. Healthy People 2000-National Health Promotion and Disease Prevention Objectives. Washington DC: US Dept of Health and Human Services. 1990.

4. Guterman L. Obesity problem swells worldwide. The Chronicle of Higher Education, 2002;:A18.

5. Anderson-Parrado P. Trim time: Five very good reasons to lose weight in 1999. Better Nutrition 1999;: 34.

6. Mokdad AH, Marks JS, Stroup DF, Gerberding JL. Actual causes of death in the United States, 2000. JAMA 2004; 291:238-1245.

7. Mokdad AH, Marks JS, Stroup DF, Gerberding JL. Correction: actual causes of death in the United States, 2000. JAMA 2005; 293:293-294

8. US Department of Health and Human Services. The Surgeon General's call to action to prevent and decrease over weight and obesity 2001. Washington, DC: US General Printing Office, 2001.

9. Hsu CY, McCulloch CE, Iribarren C, Darbinian J, Go AS. Body mass index and risk for end-stage renal disease. Ann Intern Med 2006; 144:21-28.

10. Kivipelto M, Ngandu T, Fratiglioni L, Vitanen M, Kareholt I, Winblad B, Helkala EL, Tuomilehto J, Soininen H, Nissinen A. Obesity and vascular risk factors at midlife and the risk of dementia and Alzheimer disease. Arch Neurol 2005; 62:1556-1560.

11. US Dept of Health and Human Services. Publication PHS 88-50210, Health objectives for the national prevalence of overweight among adolescents- United States 1988-91. US: US Dept of Health and Human Services. 1994.

12. Popkin BM, Paeratakul S, Zhai F, Keyou G. A review of dietary and environmental correlates of obesity with emphasis on developing countries. Obes Res 1995; 3: 145S-153S.

13. WHO. Consultation on Obesity. Geneva, Switzerland: WHO, 1997.

14. Macdonald I. Carbohydrates. In: Shils ME, Olson JA, Shike M eds. Modern Nutrition in Health and Disease. Pennsylvania: Lea \& Febiger. 1994: 36-46

15. Frels JM, Rupnow JH. Purification and partial characterization of two alpha-amylase inhibitors from black bean (Phaseolus vulgaris). J Food Biochem 1984; 1:385-401.

16. Gibbs B, Alli I. Characterization of a purified alpha-amylase inhibitor from white kidney bean (Phaseolus vulgaris). Food Research International, 1998; 31:217-225.

17. Hansawasdi C, Kawabata J, Kasai T. Alpha-amylase inhibitors from roselle (Hibiscus sabdariffa Linn) tea. Biosci Biotechnol Biochem, 2000; 64:1041-1043.

18. Hansawadi C, Kawabata J, Kasai T. Hibiscus acid as an inhibitor of starch digestion in the Caco-2 cell model system. Biosci Biotechnol Biochem, 2001; 65:2087-2089.

19. Santimone M, Koukiekolo R, Moreau Y, Le Berre V, Rouge P, Marchis-Mouren G, Desseaux V. Porcine pancreatic alpha-amylase inhibition by the kidney bean (Phaseolus vulgaris) inhibitor (Alpha-AII) and structural changes in the alpha-amylase inhibitor complex. Biochim Biophys Acta, 2004; 1696:181-190.

20. Udani J, Hardy M, Madsen DC. Blocking carbohydrate absorption and weight loss: a clinical trial using Phase 2 brand proprietary fractionated white bean extract. Altern Med Rev, 2004;9:63-69.

21. Higgins JA, Higbee DR, Donahoo WT, Brown IL, Bell ML, Bessesen DH. Resistant starch consumption promotes lipid oxidation. Nutrition and Metabolism, 2004; 1:8.

22. Nunez C, Gallagher D, Visser M, Pi-Sunyer FX, Wang Z, Heymsfield SB. Bioimpedance analysis: evaluation of leg-to-leg system based on pressure contact footpad electrodes. Med Sci Sports Exerc, 1997; 29:524-531.

23. Xie X, Kolthoff N, Barenholt O, Nielsen SP. Validation of a leg-to-leg bioimpedance analysis system in assessing body composition in postmenopausal women. Int J Obes Relat Metab Disord, 1999; 23:1079-1084.

24. Goss F, Robertson R, Williams A, Sward K, Abt K, Ladewig M, Timmer J, Dixon C. A comparison of skinfolds and leg-to-leg bioelectrical impedance for the assessment of body composition in children. Dyn Med, 2003; 26:5.

25. Vasudev S, Mohan A, Mohan D, Farooq S, Raj D, Mohan V. Validation of body fat measurement by skinfolds and two bioelectric impedance methods with DEXA - the Chennai Urban Rural Epidemiology Study. J Assoc Physicians India, 2004; 52:877-881.

26. Kaats GR, Michelak JE, Preuss HG. An evaluation of the efficacy and safety of a chitosan fiber product. J Am Coll Nutr, 2006; 25:389-394.

27. Crawford V, Scheckenbach R, Preuss HG. Effects of niacin-bound chromium supplementation on body composition of overweight African-American women. Diabetes, Obesity, and Metabolism, 1999; 1:331-337.

28. [Internet] Better Health Channel. Body Mass Index (BMI). http://www.betterhealth.vic.gov.au/bhcv2/bhcarticles.nsf/pa ges/Body_Mass_Index_(BMI)

29. Steinberger J, Jacobs DR, Raatz S, Moran A, Hong CP, Sinaiko AR. Comparison of body fatness measurements by BMI and skinfolds vs dual energy $X$-ray absorptiometry and their relation to cardiovascular risk factors in adolescents. Int J Obes, 2005; 29:1346-1352.

30. Layer P, Carlson GL, DiMagno EP. Partially purified white bean amylase inhibitor reduces starch digestion in vitro and inactivates intraduodenal amylase in humans. Gastroenenterology, 1985; 88:1895-1902.

31. Layer P, Zinsmeister AR, DiMagno EP. Effects of decreasing intraluminal amylase activity on starch digestion and postprandial gastrointestinal function in humans. Gastroenterology, 1986; 91:41-48.

32. Stohs S, Echard B, Preuss H. Inibition of carbohydrate gastrointestinal absorption in rats by various dietary supplements. J Amer Coll Nutr, 2005; 24: 426.

33. Kaats GR, Blum K, Pullin D, Keith SC, Wood R. A randomized, double-masked, placebo controlled study of the effects of chromium picolinate supplementation on body composition: a replication and extension of an earlier study. Curr Ther Res, 1998; 59: 379-388.

34. Evans GW. The effect of chromium picolinate on insulin controlled parameters in humans. Int J Biosocial Med Res, 1989; 11: 163-180.

35. Hasten DL, Rome EP, Franks BD, Hegsted M. Effects of chromium picolinate on beginning weight training students. Int $\mathrm{J}$ Sport Nutr, 1992; 2: 343-350.

36. Grant KE, Chandler RM, Castle AL, Ivy JL. Chromium and exercise training: effect on obese women. Med Sci Sports Exerc, 1997; 29: 992-998.

37. Bahadori B, Wallner S, Schneider H, Wascher TC, Toplak H. Effects of chromium yeast and chromium picolinate on body composition in obese non-diabetic patients during and after a very-Iow-calorie diet. Acta Medica Austriaca, 1997; 24: 185-187

38. Vincent JB. The potential value and toxicity of chromium picolinate as a nutritional supplement, weight loss agent and muscle development agent. Sports Med, 2003; 33:213-230.

39. Lajolo FM, Genovese MI. Nutritional significance of lectins and enzyme inhibitors from legumes. J Agric Food Chem, 2002; 50:6592-6598.

40. Grala W, Verstegen MW, Jansman A, Huisman J, van Leeusen P. Ileal apparent protein and amino acid digestibilities and endogenous nitrogen loss in pigs fed soybean and rapeseed products. J Animal Sci, 1998; 76:557-568.

41. Haidvogl M, Fritsch G, Grubauer H. Poisoning by raw garden 
Int. J. Med. Sci. 2007, 4

beans (Phaseolus vulgaris and Phaseolus coccineus) in children.

Padiatrie and Padologi 1979; 14:293

42. Rodhouse J, Haugh C, Roberts D, Gilbert R. Red kidney bean poisoning in the UK: an analysis of 50 suspected incidents between 1976 and 1989. Epidemiol Infect, 1990; 105:485-491. 